\title{
Predictors of death in infants with probable serious bacterial infection
}

Prashant Singh ${ }^{1}$, Ananya Arora ${ }^{2}$, Tor A. Strand ${ }^{3}$, Halvor Sommerfelt ${ }^{4}$, Rakesh Lodha ${ }^{5}$, Sushil Kumar Kabra ${ }^{5}$, Satinder Aneja ${ }^{6}$, Uma Chandra Mouli Natchu ${ }^{7}$, Jagdish Chandra ${ }^{6}$, Bimbadhar Rath ${ }^{6}$, Vinod Kumar Sharma ${ }^{8}$, Mohini Kumari $^{8}$, Savita Saini $^{5}$, Shinjini Bhatnagar ${ }^{7}$ and Nitya Wadhwa ${ }^{7}$

BACKGROUND: Bacterial infections account for a significant proportion of neonatal and infant mortality globally. We aimed to identify predictors of death in infants with probable serious bacterial infection (PSBI) defined as signs/symptoms of possible serious bacterial infection along with baseline C-reactive protein (CRP) $\geq 12 \mathrm{mg} / \mathrm{l}$.

METHODS: We did a secondary analysis using the data collected from 700 infants with PSBI who participated in a randomized controlled trial in India in which zinc or placebo was given in addition to the standard antibiotics. Logistic regression was used to estimate the associations between relevant variables and death within 21 days.

RESULTS: Those infants who were fed cow's milk or formula before the illness episode had 3.7-fold (95\% confidence interval (Cl) 1.5-9.3) and 5.3-fold (95\% Cl 2.0-13.6) higher odds of death, respectively. Lethargy (odds ratio (OR) $2.4,95 \% \mathrm{Cl}$ 1.1-5.4) and CRP (OR 1.9, 95\% Cl 1.1-3.3) were also independent predictors of death. In the model including only clinical features, female gender (OR 2.25, 95\% Cl 1.0-5.0), abdominal distention $(3.7,95 \% \mathrm{Cl} 1.1-12.3)$, and bulging fontanelle $(5.8,95 \%$ Cl 1.1-30.5) were also independent predictors for death.

CONCLUSION: Formula or cow milk feeding prior to the illness, lethargy at the time of presentation, and high serum CRP levels predicted death in infants with PSBI.

n 2013, about 4.6 million infants died globally and more than half ( 2.8 million) of these infant deaths occurred in the first month of life (1). Infectious causes such as sepsis, pneumonia, diarrhea, and tetanus led to over 0.6 million neonatal deaths across the world accounting for over one-fifth of all neonatal deaths $(1,2)$. In the same year, there were about 1.05 million infant deaths in India, of which 0.7 million occurred in the neonatal period (1). Compared to global data, infections accounted for an even higher proportion of neonatal deaths in India and more than one-third of neonatal deaths could be directly attributed to infections (2). Infections continue to be an important cause of death also beyond the neonatal period and are the leading cause of infant as well as under-five death (2).

Given the high neonatal and infant mortality related to sepsis and other serious bacterial infections, there is a need to identify their predictors to guide preventive and therapeutic strategies. Studies have shown that several modifiable factors such as preterm births, antenatal health care utilization, and gestational age are associated with neonatal death $(3,4)$. However, the risk factors associated with infectious causes of infant mortality are not well studied. Identifying modifiable risk factors of death in infants with serious bacterial infection may lead to program and policy changes that can further reduce infant mortality.

There is a need to identify infants with severe bacterial illness who are at increased risk of death using simple clinical and laboratory parameters at the time of presentation. In a study in an urban slum in India, less than half of the infants who needed hospitalization were actually referred (5). The same study reported that in almost $90 \%$ of the infants with serious bacterial infection, there was a delay in prescribing or administering parenteral antibiotics (5). In addition, the proportion of referred infants who actually reached the facility under the Integrated Management of Childhood Illness (IMCI) is as low as $24-42 \%$ and a substantial proportion of caretakers feel that their infant actually does not need to be admitted (5-7). Providing prognostic information to caretakers that a subset of these infants are at higher risk of death might help in increasing the proportion of infants who complete the referral. In addition, identifying predictors of death by healthcare providers may contribute to prompt referral and early parenteral antibiotics. Defining such predictors will also promote early identification of those most in need of close monitoring and critical care at tertiary care centers and also identifying high-risk groups for inclusion in clinical trials.

\footnotetext{
${ }^{1}$ Department of Medicine, Beth Israel Deaconess Medical Center, Boston, Massachusetts; ${ }^{2}$ Department of Medicine, Lady Hardinge Medical College, New Delhi, India; ${ }^{3}$ Innlandet Hospital Trust, Lillehammer, Norway; ${ }^{4}$ Centre for Intervention Science in Maternal and Child Health, Centre for International Health, University of Bergen, Bergen, Norway; ${ }^{5}$ Department of Pediatrics, All India Institute of Medical Sciences, New Delhi, India; ${ }^{6}$ Department of Pediatrics, Lady Hardinge Medical College and Kalawati Saran Children's Hospital, New Delhi, India; ${ }^{7}$ Pediatric Biology Center, Translational Health Science and Technology Institute, Gurgaon, India; ${ }^{8}$ Department of Pediatrics, Deen Dayal Upadhyay Hospital, New Delhi, India. Correspondence: Shinjini Bhatnagar (shinjini.bhatnagar@thsti.res.in) 


\section{Predictors of death in PSBI Articles}

Several studies have identified predictors of fatality in neonatal sepsis; however, similar studies in infants with serious bacterial infections are lacking $(8-11)$. Our aim was to identify predictors of death in a cohort of 700 infants with probable serious bacterial infection (PSBI) enrolled in a randomized controlled trial (12).

\section{METHODS}

\section{Study Site}

The parent study was conducted in 2005-2008 at the following three tertiary care referral centers: All India Institute of Medical Sciences, Deen Dayal Upadhyay Hospital, and Kalawati Saran Children's Hospital in New Delhi, India (12).

\section{Study Design}

Infants aged 7-120 days were screened in the emergency department for the presence of any symptoms and/or signs of possible serious bacterial infection adapted from the Integrated Management of Neonatal and Childhood Illnesses (IMNCI) strategy by the Government of India (13). If an infant had one or more clinical signs or symptoms of serious bacterial infection and did not have any of the exclusion criteria, a semi-quantitative measurement of C-reactive protein (CRP) was done using a latex agglutination test (12). If the semi-quantitative measurement of CRP was $\geq 12 \mathrm{mg} / \mathrm{l}$, infant was said to have PSBI. Infants with PSBI were included in the parent study after obtaining the written informed consent from their guardians. Infants requiring assisted ventilation, ionotropic support, exchange transfusions, and those with major congenital malformations, inborn errors of metabolism, chromosomal abnormalities, severe birth asphyxia, or serious chronic illnesses were excluded from the parent study (12). We did not have any details on outcomes of these patients and thus they could not be included in the current study.

Infants were randomly assigned in permuted blocks of six, stratified by underweight and diarrhea at enrollment. Infants received either oral zinc or placebo every day along with the standard antibiotic regimen. They were followed until recovery or 21 days, whichever was earlier (12). If the infant had not recovered within 21 days of enrollment, he or she was no longer followed by our study personnel but was continued to be treated by the hospital physicians (12). The babies' weights were measured at the time of enrollment and then every $24 \mathrm{~h}$. We recorded all deaths within the first 21 days from enrollment. Top milk feeding was defined as formula and/or cow milk feeding prior to the illness episode.

\section{Laboratory Procedures}

At the time of enrollment, blood cultures were obtained along with other laboratory investigations-hemoglobin, total leukocyte count (TLC), CRP, serum zinc, and procalcitonin (PCT). Sera was separated at the three study sites and then was transported to the central laboratory where it was stored at $-20^{\circ} \mathrm{C}$. The methodology for measurement of serum zinc levels, CRP, and PCT concentrations has been described in detail before $(12,14)$.

\section{Quality Assurance and Standardization}

Each site had a supervisor who was a trained pediatrician. They were trained in assessing eligibility, how to seek written informed consent, clinical monitoring, capturing relevant clinical,and laboratory data and determining study end points using a standardized protocol. These site supervisors in-turn trained study physicians. Three study physicians were recruited for each site such that one physician was present at the site at all times. The study physicians monitored clinical features of infants every $6 \mathrm{~h}$ or more often if required.

\section{Ethics and Consent}

Institutional Ethics Committees of each site approved the study separately. Written informed consent was obtained from guardians of infants for data collection for the randomized controlled trial. No new data collection was done for the secondary analysis. The current study did not involve any further physician-patient interaction.

\section{Statistical Analysis}

Statistical analyses were done using Stata, version 11.0 (StataCorp, College Station, TX). We used logistic regression to estimate the associations between clinically relevant variables and death. We used a commonly used manual, stepwise process to select variables that predicted death (15). CRP, PCT, hemoglobin, TLC, and serum zinc levels were analyzed as continuous variables. Except hemoglobin, other continuous variables were not normally distributed and were log-converted. Variables, which in the crude analyses were associated with death at a $P$ value of $<0.2$, were included in a multivariable logistic regression model and retained in the model if still significant at this level. Those with $P$ values $\geq 0.2$ in the crude analyses, were added back to the multivariable model one at a time. In the final model (model 1 ), we only retained variables that were significantly $(P<0.05)$ associated with our outcome. We report the odds ratios (ORs) with its $95 \%$ confidence interval (CI) for each of these variables.

CRP, PCT, and total leukocyte cell count are known acute phase reactants and thus could represent mechanisms in the causal pathway between a clinical predictor and death. To identify predictors independently of these mediators, we also developed a second multiple model (model 2) based on clinical variables alone. A number of possible interactions were assessed by including the corresponding interaction terms, such as formula milk feeding $\times$ cow milk feeding, formula milk feeding $\times$ lethargy, and cow milk feeding $\times$ lethargy in the above-mentioned final model.

\section{RESULTS}

Seven-hundred infants (245 female infants) were included in the study with a mean (standard deviation, SD) age of 54.5 (29.9) days. Twenty-seven (3.9\%) infants died within our 21day observation period.

The clinical and laboratory features of the cohort at the time of initial presentation to the study sites are shown in Table 1. Up to $40 \%$ of the infants were febrile at the time of presentation. About $37 \%$ had diarrhea and more than half had cough at the time of presentation. Three hundred seventyeight (54\%) of the infants in our study were underweight. The median (interquartile range) $\mathrm{CRP}$ and PCT concentrations were $33.7(18.4,61.2) \mathrm{mg} / \mathrm{l}$ and $0.99(0.44,4.8) \mu \mathrm{g} / \mathrm{l}$, respectively.

\section{Model 1}

Of the baseline variables listed in Table 1, 13 variables were associated with death at $P<0.2$ and were included in the multivariable model (Table 2). In the final model, history of cow milk feeding before the illness episode (OR 3.7, 95\% CI 1.5-9.3; $P=0.006$ ), formula milk feeding before the illness episode (OR 5.3, 95\% CI 2.0-13.6, $P=0.001$ ), lethargy on physical examination (OR 2.4, 95\% CI 1.1-5.4, $P=0.03$ ), and $\log$ CRP (OR 1.9, 95\% CI 1.1-3.3, P 0.02) were independent predictors of death (Table 3 ). When formula feeding and cow milk feeding were replaced by the variable indicating top milk feeding, the final model remained almost identical and top milk remained an independent predictor of death (OR 5.4, 95\% CI 2.1-13.5, $P<0.001)$. 
Table 1. Baseline clinical, anthropometric and laboratory details of 7120 day old infants with probable serious bacterial infection

Demographic details
Age (days); mean (SD)
Clinical history
Irritability
Excessive cry
Diarrhea
Blood in stools
Vomiting
Cough
Convulsions
History of breast milk feeding prior to the
episode
History of cow milk feeding prior to the
episode
History of formula milk feeding prior to the
episode
History of cow milk feeding in last $24 \mathrm{~h}$
History of formula milk feeding in last $24 \mathrm{~h}$
History of prior antibiotic treatment in the
current episode
Anthropometry
Weight for age less than $-2 \mathrm{z}$

$230(32.9 \%)$

$275(39.3 \%)$

$256(36.6 \%)$

15 (2.1\%)

141 (20.1\%)

$358(51.1 \%)$

$59(8.4 \%)$

$569(81.3 \%)$

$178(25.4 \%)$

$112(16 \%)$

$154(22.4 \%)$

$92(13.4 \%)$

$141(20.1 \%)$

375 (53.6\%)

$\begin{array}{lc}\text { Physical examination } & \\ \text { Fever } & 2729(39.9 \%) \\ \text { Lethargy on physical examination } & 208(29.7 \%) \\ \text { Good sucking at breast } & 441(63 \%) \\ \text { Fast breathing }^{\mathrm{a}} & 351(50.1 \%) \\ \text { Crepitations } & 275(39.3 \%) \\ \text { Abdominal distention } & 36(5.1 \%) \\ \text { Some dehydration } & 63(9 \%) \\ \text { Bulging fontanelle } & 18(2.6 \%)\end{array}$

Laboratory parameters

Positive blood cultures

$88(12.6 \%)$

Hemoglobin; g/dl

$11.2 \pm 3$

TLC; per $\mu$ l of blood

Serum CRP; mg/l

$11,000(8,000-15,510)$

33.7 (18.4-61.2)

Serum PCT; $\mathrm{ng} / \mathrm{ml}$

$0.99(0.44-4.8)$

Serum zinc level; $\mu \mathrm{g} / \mathrm{dl}$

$63.4(49.7-79.8)$

Randomization to zinc group

CRP, C-reactive protein; $P C T$, procalcitonin; $S D$, standard deviation; $T L C$, total leukocyte count; Z-score (or SD-score), observed value - median value of the reference population/standard deviation value of reference population.

Data are mean $( \pm \mathrm{SD})$, median (IQR) and $n(\%)$.

${ }^{a} \geq 60$ breaths per min for infants $<2$ months; $\geq 50$ breaths per min for infants $\geq 2$ months.
Several studies have used cutoffs in the range of CRP concentrations of $40 \mathrm{mg} / \mathrm{l}$ in an attempt to indicate likelihood of bacterial infections. We also analyzed our data after dichotomizing CRP levels to $<40$ and $\geq 40 \mathrm{mg} / \mathrm{l}$. In this analysis, we found that clinical predictors for death from PSBI and the odds for death for each variable remained unchanged and that infants with CRP $\geq 40 \mathrm{mg} / \mathrm{l}$ had a 4.1 -fold increased odds of dying. ( $95 \% \mathrm{CI}-1.7$ to $10.0, P=0.002$ ). The area under the receiver-operating characteristic (ROC) curve for this model was 0.84 .

\section{Model 2}

When the three variables (CRP, PCT, and total leukocyte count) were not included in the regression model, 11 variables were associated with death at $P<0.2$ and were included in the multivariable model. In this final model, similar to Model 1, lethargy on physical examination, cow milk feeding before the illness, and formula milk feeding before the illness continued to be the independent predictors of death (Table 4). In addition, female gender (OR 2.25, 95\% CI 1.0-5.0, $P=0.047$ ), clinical features at the time of presentation such as abdominal distention on physical examination $(3.7,95 \% \mathrm{CI}-1.1$ to 12.3 , $P=0.03$ ) and bulging fontanelle on physical examination (5.8, $95 \%$ CI $1.1-30.5, P=0.04)$ significantly predicted death in infants with PSBI. The area under the ROC curve for this model was 0.79 .

\section{Subgroup Analysis by Diarrhea}

As several studies have shown protective effect of exclusive breastfeeding against diarrhea-specific morbidity and mortality in infants, we performed a subgroup analysis to determine whether the detrimental effects of cow milk/formula were limited to those patients who had diarrhea. When we applied our predictive model to infants stratified by the presence or absence of diarrhea, we found that cow milk feeding and formula feeding prior to the illness episode continued to be the significant predictors of death in infants without diarrhea (5.6, 95\% CI 1.6, 20.4, $P=0.008$ and 5.8, 95\% CI 1.5, 23.1, $P=0.01$, respectively).

\section{DISCUSSION}

Death from serious bacterial infection is one of the most common causes of infant mortality in the developing world and most of these deaths are preventable $(1,2)$. Using a data set of 700 infants with suspected serious bacterial infections, we identified clinical and laboratory predictors for death in these infants (12).

All infants in our study were less than 4 months of age, an age group in which the World Health Organization (WHO) recommends exclusive breastfeeding (16). However, more than $40 \%$ received other feeds. We found that infants who had received cow milk prior to the illness episode had 3.7 times increased odds of dying from the PSBI when compared with those who had not. Similarly, the odds of death were 5.3 times higher in infants who were formula fed. The ORs for formula feeding and cow milk feeding were not altered when the 
Table 2. Univariable analysis using logistic regression to identify variables associated with death in 7-120-day-old infants with probable serious bacterial infection

\begin{tabular}{|c|c|c|c|c|c|}
\hline & Deaths (\%) & Surviving patients (\%) & Odds ratio & 95\% Confidence interval & $P$ value \\
\hline \multicolumn{6}{|l|}{ Demographics } \\
\hline Female gender ${ }^{a}$ & $15(6.1)$ & $230(93.9)$ & 2.4 & $1.1-5.2$ & 0.03 \\
\hline \multicolumn{6}{|l|}{ Clinical symptoms } \\
\hline Excessive cry ${ }^{\mathrm{a}}$ & $7(2.5)$ & $268(97.5)$ & 0.5 & $0.2-1.3$ & 0.15 \\
\hline Diarrhea $^{\mathrm{a}}$ & $14(5.5)$ & $242(94.5)$ & 1.9 & $0.9-4.1$ & 0.10 \\
\hline Blood in stools & $1(6.7)$ & $14(93.3)$ & 1.9 & $0.2-14.8$ & 0.56 \\
\hline Vomiting & $3(2.1)$ & $138(97.9)$ & 0.5 & $0.1-1.6$ & 0.24 \\
\hline \multicolumn{6}{|l|}{ Relevant history } \\
\hline History of breast milk feeding prior to illness episode $\mathrm{a}^{\mathrm{a}}$ & $17(3.0)$ & $552(97.0)$ & 0.4 & $0.2-0.8$ & 0.02 \\
\hline History of cow milk feeding prior to illness episode ${ }^{a}$ & $11(6.2)$ & $167(93.8)$ & 3.2 & $1.4-7.3$ & 0.004 \\
\hline History of formula milk feeding prior to illness episode ${ }^{a}$ & $10(8.9)$ & $102(91.1)$ & 2 & $0.9-4.5$ & 0.08 \\
\hline History of formula milk feeding in last $24 \mathrm{~h}^{\mathrm{a}}$ & $8(8.7)$ & $84(91.3)$ & 2.9 & $1.2-6.8$ & 0.015 \\
\hline History of cow milk feeding in last $24 \mathrm{~h}^{\mathrm{a}}$ & $9(5.8)$ & $145(94.2)$ & 1.8 & $0.8-4$ & 0.170 \\
\hline History of prior antibiotic treatment in the current episode & $5(3.5)$ & $136(96.5)$ & 1.0 & $0.9-1.0$ & 0.25 \\
\hline \multicolumn{6}{|l|}{ Anthropometry } \\
\hline Crepitations & $10(3.6)$ & $265(96.4)$ & 0.9 & $0.4-2.0$ & 0.80 \\
\hline Abdominal distention ${ }^{a}$ & $4(11.1)$ & $32(88.9)$ & 3.5 & $1.1-10.7$ & 0.03 \\
\hline Bulging fontanelle ${ }^{a}$ & $2(11.1)$ & $16(88.9)$ & 3.3 & $0.7-15.1$ & 0.13 \\
\hline Some dehydration & & & 1.3 & $0.4-4.4$ & 0.70 \\
\hline \multicolumn{6}{|l|}{ Laboratory parameters } \\
\hline Positive blood cultures & & & 1.3 & $0.4-4$ & 0.61 \\
\hline Log hemoglobin & & & 0.4 & $0.1-1.7$ & 0.23 \\
\hline Log TLC & & & 1.5 & $0.8-3.0$ & 0.25 \\
\hline $\log C R P^{a}$ & & & 1.9 & $1.1-3.2$ & 0.02 \\
\hline $\log P C T^{a}$ & & & 1.3 & $1.1-1.8$ & 0.02 \\
\hline Zinc at baseline & & & 0.7 & $0.2-2.0$ & 0.48 \\
\hline Randomization to zinc group ${ }^{a}$ & $10(2.8)$ & $342(97.2)$ & 0.6 & $0.2-1.3$ & 0.17 \\
\hline
\end{tabular}

CRP, C-reactive protein; PCT, procalcitonin; TLC, total leukocyte count.

a Variables included in multivariable logistic regression analysis because their $P$ values were $<0.2$

${ }^{b} \geq 60$ Breaths per min for infants $<2$ months; $\geq 50$ breaths per min for infants $\geq 2$ months. 


\section{Articles | singh et al.}

Table 3. Baseline clinical and laboratory characteristics found in multivariable logistic regression to be associated with death in 7-120day-old infants with probable serious bacterial infection based on all the variables listed in Tables 1 and $\mathbf{2}$

\begin{tabular}{|c|c|c|c|}
\hline & $\begin{array}{l}\text { Odds } \\
\text { ratio }\end{array}$ & $\begin{array}{l}\text { 95\% Confidence } \\
\text { interval }\end{array}$ & $P$ value \\
\hline \multicolumn{4}{|l|}{ Relevant history } \\
\hline $\begin{array}{l}\text { History of cow milk } \\
\text { feeding prior to episode }\end{array}$ & 3.7 & $1.5-9.3$ & 0.006 \\
\hline $\begin{array}{l}\text { History of formula milk } \\
\text { feeding prior to episode }\end{array}$ & 5.3 & $2.0-13.6$ & 0.001 \\
\hline \multicolumn{4}{|l|}{ Physical exam } \\
\hline $\begin{array}{l}\text { Lethargy on physical } \\
\text { examination }\end{array}$ & 2.4 & $1.1-5.4$ & 0.03 \\
\hline \multicolumn{4}{|l|}{ Laboratory parameters } \\
\hline $\log$ CRP & 1.9 & $1.1-3.3$ & 0.015 \\
\hline
\end{tabular}

Table 4. Baseline clinical characteristics found in multivariable logistic regression to be associated with death in 7-120-day-old infants with probable serious bacterial infection based on all the variables listed in Table 1 except for C- reactive protein, procalcitonin and total white count

\begin{tabular}{lccc}
\hline & $\begin{array}{c}\text { Odds } \\
\text { ratio }\end{array}$ & $\begin{array}{c}95 \% \text { Confidence } \\
\text { interval }\end{array}$ & P value \\
\hline $\begin{array}{l}\text { Demographic details } \\
\text { Female gender }\end{array}$ & 2.3 & $1.0-5.0$ & 0.047 \\
$\begin{array}{l}\text { Relevant history } \\
\begin{array}{l}\text { History of cow milk } \\
\text { feeding prior to episode }\end{array}\end{array}$ & 3.7 & $1.5-9.3$ & 0.006 \\
$\begin{array}{l}\text { History of formula milk } \\
\text { feeding prior to episode }\end{array}$ & 5.3 & $2.0-13.6$ & 0.001 \\
$\begin{array}{l}\text { Physical exam } \\
\begin{array}{l}\text { Lethargy on physical } \\
\text { examination }\end{array}\end{array}$ & 2.4 & & \\
$\begin{array}{l}\text { Abdominal distention on } \\
\text { physical examination }\end{array}$ & 3.7 & $1.1-5.4$ & 0.03 \\
$\begin{array}{l}\text { Bulging fontanelle on } \\
\text { physical examination }\end{array}$ & 5.8 & $1.1-12.3$ & 0.03 \\
\hline
\end{tabular}

laboratory parameters were not included in the model. This is in line with previous findings from the same data set, where formula feeding was associated with prolonged time to recovery from PSBI (14). This is also in accordance with the current literature that exclusive breastfeeding decreases mortality from diarrhea, acute respiratory infections such as pneumonia and all-cause mortality in infants (17-20). These findings emphasize the health benefits of exclusive breastfeeding in early infancy. This could be because human milk has several unique factors that are anti-infective or have immunological properties-secretory immunoglobulin A, lactoferrin, anti-infective enzymes such as lysozymes, and numerous cytokines (21). In addition, the associations between top milk feeding and case fatality could also be due to direct adverse effects of cow milk such as occult gastrointestinal blood loss, intestinal mucosal inflammation as well as high renal solute load leading to the possibility of severe dehydration at the time of decreased oral intake or increased water loss due to fever or diarrhea $(22,23)$. Some of the deleterious effects of cow milk such as high renal solute load could also be seen with formula feeds (24). The variables "formula/cow milk feeding prior to the episode" and "formula/cow milk feeding in the last $24 \mathrm{~h}$ " were collinear and not included in the multiple models simultaneously. However, when we built a predictive model using formula/ cow milk feeding in the last $24 \mathrm{~h}$ (excluding formula/cow milk feeding prior to the episode) and other variables in Table 2, the final predictive model included the same clinical and laboratory variables described above but not formula/cow milk feeding in the last $24 \mathrm{~h}$ in the final model. This suggests that the association between top feeding and death is not due to the altered feeding practices during the episode of acute illness. This does not completely rule out reverse causality but makes it more unlikely. In addition, there is a possibility of residual confounding, as feeding practices may also be related to socioeconomic factors that increase the risk of death by themselves. Several studies have shown that several maternal factors (age, parity, education level, monthly income, access to healthcare, and so on) are closely associated with infant feeding practices $(25,26)$. It is possible that some of these factors such as maternal education, socioeconomic status, access to healthcare could be independently associated with infant death due to PSBI. In our study, the practice of top feeding prior to the illness episode was not associated with maternal schooling or with high school education level. Another study in India found that breastfeeding habits were associated with other demographic variables such as number of children, family size but not with maternal education (27). Our study did not capture these variables well and it was accordingly not possible to examine whether these factors could confound the feeding variables.

Among infants with PSBI, those who were lethargic, had abdominal distention, or had bulging fontanelle on initial physical examination had a significantly increased risk of death. We have previously shown that lethargy also predicts prolonged time to recovery in infants with PSBI (14). Bulging anterior fontanelle in infants is likely to indicate meningitis that is associated with a poorer prognosis. These simple clinical signs could be used at primary and secondary health care centers to predict death in infants with PSBI and thus would be useful as prognostic information for community health workers and clinicians to initiate and complete the referral and to make sure they receive early antibiotics before being transported to a health facility.

We also found that girls had a poorer prognosis than boys in that they had a 2.3 times higher odd of dying from PSBI as 
compared to boys. In India, girls on an average have lower vaccination coverage, poorer nutritional status, and receive lesser medical attention later, also for life-threatening illnesses (28). A large study on pediatric patients in India showed significantly higher mortality among female children admitted to the hospital as well as a shorter survival period between hospital admission to death, indicating that they were brought later in the course of the illness $(29,30)$. Similar to the previous studies, poor prognosis of girl babies in our study could be due to gender discrimination leading to a delay in medical care for the female infants. There is a need for policies and action that focus on eliminating gender discrimination in pediatric healthcare.

Although higher CRP levels has been shown to predict death in adults and neonates with bacteremia and/or sepsis, this has not been studied rigorously in infants with sepsis $(14,31-36)$. We recently reported that CRP level in infants with PSBI was linearly associated with the duration of hospitalization (14). This study shows that higher CRP level is also associated with death in infants with PSBI. This important finding could be used to recommend CRP as a simple tool for predicting poor outcomes in infants admitted with features of PSBI and thus help in decision-making for clinical management. However, as discussed above, elevated CRP reflects inflammation, which could be in the causal pathway of clinical predictors and death. For this reason and to inform guidelines that would be independent of laboratory examinations, we also developed a model without using CRP and other laboratory markers.

Our study has a few limitations. We only included infants who, in addition to symptoms and signs of possible serious bacterial infection, had elevated serum CRP concentrations. In addition, due to the study design of the parent study, many infants with likely serious bacterial infections such as those requiring mechanical ventilation or ionotropic support were excluded from this study. Thus, our cohort might not represent all the infants with possible serious bacterial infection. Similarly, it is also possible that many of the infants included in our study did not have bacterial infections. Preterm infants were included in the parent study only when they were more than 2 months of age and thus our study population does not represent this group well. One-fifth of the infants had received antibiotics before presenting to the study sites and this could have resulted in negative blood cultures in some cases, thus limiting our ability to assess it as a prognostic marker. This, however, cannot be avoided as IMNCI guidelines recommend that infants with possible serious bacterial infection should receive the first dose of antibiotics before hospitalization and is part of routine care $(13,14)$.

We identified clinical symptoms and signs predicting death in infants with probable sepsis. When available, CRP could assist physicians and health care workers in identifying infants at the highest risk of sepsis-related fatality. Some of the risk factors of death in infants with sepsis such as lack of exclusive breastfeeding are modifiable. Future studies validating these predictors in other cohorts of infants and neonates with serious bacterial infections are needed.

Disclosure: The authors declare no conflict of interest.

\section{REFERENCES}

1. Levels and trends in child mortality-report 2014. Estimates Developed by the UN Inter-agency Group for Child Mortality Estimation. UNICEF: New York, 2014.

2. The Million Death Study Collaborators, Bassani DG, Kumar R, et al. Causes of neonatal and child mortality in India: a nationally representative mortality survey. Lancet 2010;376:1853-60.

3. Jehan I, Harris H, Salat S, et al. Neonatal mortality, risk factors and causes: a prospective population-based cohort study in urban Pakistan. Bull World Health Organ 2009;87:130-8.

4. Batieha AM, Khader YS, Berdzuli N, et al. Level, causes and risk factors of neonatal mortality, in Jordan: results of a National Prospective Study. Matern Child Health J 2016;20:1061-71.

5. Bhandari N, Bahl R, Taneja S, Martines J, Bhan MK. Pathways to infant mortality in urban slums of Delhi, India: implications for improving the quality of community- and hospital-based programmes. J Health Popul Nutr 2002;20:148-55.

6. Bhandari N, Bahl R, Bhatnagar V, Bhan MK. Treating sick young infants in an urban slum setting. Lancet 1996;347:1774-5.

7. Kalter HD, Salgado R, Moulton LH, et al. Factors constraining adherence to referral advice for severely ill children managed by the Integrated Management of Childhood Illness approach in Imbabura Province, Ecuador. Acta Paediatr 2003;92:103-10.

8. Venkataseshan S, Dutta S, Ahluwalia J, Narang A. Low plasma protein C values predict mortality in low birth weight neonates with septicemia. Pediatr Infect Dis J 2007;26:684-8.

9. Ogunlesi TA, Ogunfowora OB. Predictors of mortality in neonatal septicemia in an underresourced setting. J Natl Med Assoc 2010;102: 915-21.

10. Kayange N, Kamugisha E, Mwizamholya DL, Jeremiah S, Mshana SE. Predictors of positive blood culture and deaths among neonates with suspected neonatal sepsis in a tertiary hospital, Mwanza-Tanzania. BMC Pediatr 2010;10:39.

11. Zakariya BP, Bhat B V, Harish BN, Arun Babu T, Joseph NM. Risk factors and predictors of mortality in culture proven neonatal sepsis. Indian $J$ Pediatr 2012;79:358-61.

12. Bhatnagar S, Wadhwa N, Aneja S, et al. Zinc as adjunct treatment in infants aged between 7 and 120 days with probable serious bacterial infection: a randomised, double-blind, placebo-controlled trial. Lancet 2012;379:2072-8.

13. Ministry of Health and Family Welfare, Government of India Integrated management of neonatal and childhood illness: Assess and classify the sick young infant age upto 2 months. (2009) (http://nrhm.gov.in/images/ pdf/programmes/child-health/guidelines/module_2.pdf).

14. Singh P, Wadhwa N, Lodha R, et al. Predictors of time to recovery in infants with probable serious bacterial infection. PLoS ONE 2015;10: e0124594.

15. Hosmer DW, Lemeshow S. Applied Logistic Regression. New York, USA: John Wiley and Sons, 2000.

16. World Health Organization Infant and young child nutrition. 2002 (http://apps.who.int/gb/archive/pdf_files/WHA55/ea5515.pdf) Accessed 8 June 2015.

17. Rollins NC, Ndirangu J, Bland RM, Coutsoudis A, Coovadia HM, Newell ML. Exclusive breastfeeding, diarrhoeal morbidity and all-cause mortality in infants of HIV-infected and HIV uninfected mothers: an intervention cohort study in KwaZulu Natal, South Africa. PLoS ONE 2013;8:e81307.

18. Arifeen S, Black RE, Antelman G, Baqui A, Caulfield L, Becker S. Exclusive breastfeeding reduces acute respiratory infection and diarrhea deaths among infants in Dhaka slums. Pediatrics 2001;108:E67. 


\section{Articles | singh et al.}

19. Lamberti LM, Zakarija-Grković I, Fischer Walker CL, et al. Breastfeeding for reducing the risk of pneumonia morbidity and mortality in children under two: a systematic literature review and meta-analysis. BMC Public Health 2013;13 (Suppl 3): S18.

20. Lamberti LM, Fischer Walker CL, Noiman A, Victora C, Black RE. Breastfeeding and the risk for diarrhea morbidity and mortality. BMC Public Health 2011;11 (Suppl 3): S15.

21. Chirico G, Marzollo R, Cortinovis S, Fonte C, Gasparoni A. Antiinfective properties of human milk. J Nutr 2008;138:1801S-6S.

22. Agostoni C, Turck D. Is cow's milk harmful to a child's health? J Pediatr Gastroenterol Nutr 2011;53:594-600.

23. Ziegler EE. Adverse effects of cow's milk in infants. Nestle Nutr Workshop Ser Pediatr Program 2007;60:185-99.

24. Ziegler EE, Fomon SJ. Potential renal solute load of infant formulas. J Nutr 1989;119:1785-8.

25. Victor R, Baines SK, Agho KE, Dibley MJ. Determinants of breastfeeding indicators among children less than 24 months of age in Tanzania: a secondary analysis of the 2010 Tanzania Demographic and Health Survey. BMJ Open 2013;3: pii e001529.

26. Bærug A, Laake P, Løland BF, Tylleskär T, Tufte E, Fretheim A. Explaining socioeconomic inequalities in exclusive breast feeding in Norway. Arch Dis Child 2017;102:708-14.

27. Radhakrishnan S, Balamuruga SS. Prevalence of exclusive breastfeeding practices among rural women in Tamil Nadu. Int J Health Allied Sci 2012;1:64-7.
28. Khera R, Jain S, Lodha R, Ramakrishnan S.. Gender bias in child care and child health: global patterns. Arch Dis Child 2014;99:369-74.

29. Sachar RK, Verma J, Dhawan S, Prakash V, Chopra A, Adlaka R. Sex bias in health and medical care allocation. Indian J Matern Child Health 1990;1:63-5.

30. Verma J, Sachar RK, Dhawan S, Prakash V. Gender differences in health care. J Trop Pediatr 1990;36:205-6.

31. Bilavsky E, Yarden-Bilavsky H, Ashkenazi S, Amir J. C-reactive protein as a marker of serious bacterial infections in hospitalized febrile infants. Acta Paediatr 2009;98:1776-80.

32. Hofer N, Zacharias E, Müller W, Resch B. An update on the use of C-reactive protein in early-onset neonatal sepsis: current insights and new tasks. Neonatology 2012;102:25-36.

33. Andreola B, Bressan S, Callegaro S, Liverani A, Plebani M, Da Dalt L. Procalcitonin and $\mathrm{C}$-reactive protein as diagnostic markers of severe bacterial infections in febrile infants and children in the emergency department. Pediatr Infect Dis J 2007;26:672-7.

34. Devran O, Karakurt Z, Adigüzel N, et al. C-reactive protein as a predictor of mortality in patients affected with severe sepsis in intensive care unit. Multidiscip Respir Med 2012;7:47.

35. Lobo SM, Lobo FR, Bota DP, et al. C-reactive protein levels correlate with mortality and organ failure in critically ill patients. Chest 2003;123:2043-9.

36. Gradel KO, Thomsen RW, Lundbye-Christensen S, Nielsen $H$, Schønheyder HC. Baseline C-reactive protein level as a predictor of mortality in bacteaemia patients: a population-based cohort study. Clin Microbiol Infect 2011;17:627-32. 